\title{
A new short version of the Cognitive Therapy Scale Revised (CTSR-4): preliminary psychometric evaluation
}

Sven Alfonsson ${ }^{1,2^{*}}$, Georgios Karvelas ${ }^{1,2}$, Johanna Linde ${ }^{1,2}$ and Maria Beckman ${ }^{1,2}$

\begin{abstract}
Background: The value of using comprehensive but cumbersome coding instruments to assess therapeutic competency is unclear. Shorter, more general instruments may enable more research in this important area. The aim of this study was therefore to psychometrically evaluate a shorter version of the Cognitive Therapy Scale-Revised (CTSR) and to compare it with the full-length version.

Methods: A four-item coding instrument (the CTSR-4) was derived from the CTSR. Four experienced psychotherapists used the CTSR-4 to assess 50 fifteen-minutes samples from audio-recorded CBT sessions. The criterion validity of the CTSR-4 was analyzed by comparing the results with previously expert-rated CTSR scores from the same sessions, and the inter-rater agreement between the three coders was calculated.

Results: The CTSR-4 showed good criterion validity (ICC $=.71-.88)$ when compared to the expert ratings of the complete CTSR, and the inter-rater agreement was adequate $(\mathrm{ICC}=.64-.79)$.

Conclusions: A condensed version of the CTSR, used to assess CBT competence from shorter samples of therapy sessions, is moderately reliable and may provide similar results as the full-length version. According to preliminary analyses, the CTSR-4 has potential as a low-cost alternative to assess CBT competency in both research and psychotherapist training.
\end{abstract}

Keywords: CBT, Therapist competence, Psychotherapy training, Psychometrics

\section{Introduction}

Over the years, much effort has been put into conceptualizing and defining psychotherapy competence in order to make it measurable $[1,2]$. These efforts are also central to psychotherapist training, as it is assumed that competent therapists more efficiently treat patients [3]. Still, the relationship between therapists' competence and clinical outcomes is far from clear $[4,5]$. To provide more research in this area, adequate coding instruments are crucial. However, comprehensive and detailed measures

\footnotetext{
${ }^{*}$ Correspondence: sven.alfonsson@ki.se

${ }^{1}$ Centre for Psychiatry Research, Department of Clinical Neuroscience,

Karolinska Institutet, 17177 Stockholm, Sweden

Full list of author information is available at the end of the article
}

of therapeutic competencies are resource-consuming, and the question is whether briefer and more general measures can provide satisfactory data to accurately assess therapeutic skills.

The Cognitive Therapy Scale (CTS) [6], or its revised version (CTSR), are the most used instruments in studies of CBT and its relation to patient outcome [7, 8]. However, the model of cognitive therapy (i.e., not empirical studies), and the ability to predict patient outcomes with the instruments is unclear [9]: Studies by Trepka et al. [10], Kazantzis et al. [11], Kuyken and Tsivrikos [12], and Liness et al. [13], found only weak associations between CBT competence and patient outcome, and Weck et al. [14], Bruijniks et al. [15] and Liness et al. [16] found no 
such associations. These ambiguous results highlight the question of how CBT competence should be measured, as well as the question of the impact of specific therapist skills on patient outcomes $[17,18]$.

A possible explanation for the inconclusive associations between CBT competence and patient outcome could be other mediating variables, such as the therapeutic alliance [19]. Another explanation could be that the associations are not linear-once a therapist competence level sufficient to help most patients, no further increase lead to improved patient outcome [13, 20, 21]. It is also possible that most patients' needs are met by therapists of moderate competence, and that only a small group of patients require therapists with higher levels of competence [22-24]. These types of more detailed analyzes of CBT competence and patient outcomes are highly needed, but are hampered by the costs of coding instruments that analyze full sessions (e.g., CTSR). A more efficient alternative could be to analyze session samples. Weck et al. [25] assessed general competence rather accurately from either the start, middle, or end of CBT sessions. The specific skills, however, was more difficult to assess (e.g., homework could not be assessed from an initial part of a session). This problem could be minimized by selecting several shorter samples from a single session (e.g., start, middle and end).

Existing frameworks for psychotherapy competence propose a handful of general competencies, including theoretical knowledge, and the ability to engage patients, establish a working relationship, and transform theoretical knowledge into clinical practice [26, 27]. CBT also includes specific competencies, such as the structure of sessions and use of guided discovery. Competence measurements, such as the CTSR, typically include both general and specific competencies. Whether the effects of psychotherapy are best explained by specific- or general competencies is unknown $[18,28,29]$, and no CBT study have yet found a specific competence highly associated with outcome. This may partly be explained by the fact that competence instruments, such as the CTSR, typically show high internal consistency, which questions the value of rating competence in numerous closely related subdomains [30]. A short instrument that rates therapists' competence on a few selected global variables could be more efficient.

Briefer and more general instruments for CBT competence may both be more efficient and cost-effective. An important research question is therefore whether such less resource-consuming measures of therapy competence can show adequate psychometric properties. The aim of this study was to assess the criterion validity and inter-rater agreement of the CTSR-4, a brief instrument derived from the CTSR.

\section{Materials and methods}

The criterion validity of the CTSR- 4 was assessed by comparing scores from the CTSR-4 with previously independently assessed CTSR scores of the same CBT sessions. The inter-rater reliability of the CTSR-4 was assessed by comparing scores between independent coders for each session sample.

\section{The CTSR-4}

The CTSR-4 was derived directly from the CTSR [7]. The CTSR comprises twelve items: Agenda Setting and adherence; Collaboration; Guided discovery; Feedback; Conceptual integration; Eliciting key cognitions; Eliciting appropriate emotional expression; Eliciting and planning behaviors; Application of change methods; Interpersonal effectiveness; Pacing and efficient use of time; and Homework setting. Although more research is needed, it is noteworthy that previous studies have suggested various factor structures of the CTSR without coming to a consensus and typically only the total score is calculated [9, 30, 31]. Each item is scored on a 7-point Likert scale from 0 to 6 . A score of 0 indicates none or highly inadequate competence, 1-2 indicates inadequate competence, 3-4 indicates adequate competence, and a score of 5-6 indicates an expert level of competence in the corresponding domain. In the CTSR-4, the twelve CTSR items were merged into four items, each corresponding to three of the CTSR items; Structure, Therapeutic relation, Conceptual integration and Therapeutic change (Fig. 1). This four-factor structure was discussed and decided upon among the study authors and inspired by other researchers who have vented similar ideas [26]. The four items of the CTSR- 4 arguably map well with the CBT competence framework [27]. Each item of the CTSR-4 is scored on a 7-point Likert scale from 0 to 6 and the total score can range from 0 to 24 . A brief six-page scoring manual was developed, in which the CTSR-4 item descriptions and examples were provided to cover the broader scope of each item.

\section{Procedure}

Four coders participated in this study. Two coders (A and B) assessed all 50 session samples while two coders (C and D) coded 20 and 30 session samples respectively. All coders had advanced level training in psychotherapy, had previously used the CTSR, and three of them were teaching university CBT courses and providing clinical supervision. The coders met for five to ten 90-min training sessions in different compositions, during which the CTSR-4 was discussed, and twelve audio recorded CBT sessions were coded independently and compared. Discrepancies in coding results were discussed to reach a consensus before the next training session. These 


\begin{tabular}{|ll|}
\hline CTSR-4 item & CTSR items \\
\hline Structure & Agenda Setting and adherence \\
Pacing and efficient use of time \\
Therapeutic relation & Feedback \\
& Collaboration \\
Conceptual integration & Eliciting appropriate emotional expression \\
Interpersonal effectiveness \\
Conceptual integration \\
Eliciting key cognitions \\
Eliciting and planning behaviours \\
Therapeutic change
\end{tabular}

Fig. 1 The items of the CTSR-4 and the corresponding CTSR items

recordings were only for training and were not used for further analyses. Over the training sessions, the interrater agreement increased among the coders and was eventually deemed adequate to independently code sessions. Inter-rater agreement could not be adequately statistically analyzed in the small training sample. Each coder received the manual and scoring sheets, and was instructed to listen to and independently assess the fifteen-minute session samples, and use approximately a total of $20 \mathrm{~min}$ for each assessment. The coders had additional meetings throughout the coding period to discuss the CTSR-4 items.

The 50 CBT sessions were randomly drawn from a set of 120 audio-recorded sessions, previously coded in full by independent expert raters using the CTSR. The expert raters were two CBT supervisors with more than fifteen years of clinical experience. They had had formal training in using the CTSR, and several years of experience in using the CTSR in psychotherapy training and supervision but were not part of the research team. The recorded CBT sessions were collected from six therapists working in open psychiatric care and included patients with different mood disorders and related problems. All therapists and patients had provided informed consent to participate in the study, and the study was approved by the Regional Ethics Committee Board (No.
2018/1735-31/3). The therapy sessions followed standard practice and comprised interventions and procedures common in mainstream CBT, such as Socratic dialogue, cognitive exercises, behavioral experiments, exposure exercises, problem-solving, and homework assignments. For this study, five minutes from the start (minutes 0-5) middle (typically minutes 22-27), and the end (typically minutes 45-50) were extracted for a total session sample of $15 \mathrm{~min}$ from each of the 50 CBT recordings. The recordings were blindly selected but edited so that only actual treatment time was included (e.g., recordings after the session had ended, where the therapist guided the patient back to the waiting room, was removed). Each edited 15-min recording was then given a random identifying number and provided to three of the four independent coders. Each recording was thus randomly distributed and coded by three of the four coders.

\section{Analysis}

To be able to compare the results from the four items of the CTSR-4 with the full CTSR, the mean for the corresponding item scores from the CTSR was calculated. The scores were then rounded off to the nearest 0.5 -value to facilitate statistical comparisons. To assess the criterion validity and inter-rater reliability of the CTSR-4, a two-way, random effects, absolute agreement model of 
Table 1 Expert rater and coder mean values, standard deviations and range for each CTSR-4 item

\begin{tabular}{lccccc}
\hline $\begin{array}{l}\text { CTSR-4 } \\
\text { item }\end{array}$ & $\begin{array}{l}\text { CTSR expert raters } \\
\mathbf{m}(\mathbf{S D}), \text { range }\end{array}$ & $\begin{array}{l}\text { Coder A } \\
\mathbf{m}(\mathbf{S D}), \text { range }\end{array}$ & $\begin{array}{l}\text { Coder B } \\
\mathbf{m}(\mathbf{S D}), \text { range }\end{array}$ & $\begin{array}{l}\text { Coder C } \\
\mathbf{m} \text { (SD), range }\end{array}$ & $\begin{array}{l}\text { Coder D } \\
\mathbf{m} \text { (SD), range }\end{array}$ \\
\hline Structure & $3.2(0.70), 1.0-4.5$ & $3.3(0.78), 1.0-5.0$ & $3.2(0.98), 1.0-4.5$ & $3.5(0.81), 1.5-5.0$ & $3.4(0.84), 1.5-5.0$ \\
Relation & $3.5(0.86), 1.0-5.0$ & $3.5(0.76), 1.0-5.0$ & $3.4(0.98), 2.0-5.0$ & $3.5(0.80), 2.0-5.0$ & $3.4(0.76), 2.0-5.0$ \\
Concept & $3.2(0.95), 0.5-5.0$ & $3.3(1.00), 1.0-4.5$ & $3.4(1.14), 1.0-5.0$ & $3.2(1.12), 1.0-5.0$ & $2.9(1.14), 1.0-5.0$ \\
Change & $3.4(0.95), 1.0-5.0$ & $3.5(1.01), 1.0-5.0$ & $3.4(1.14), 1.0-5.0$ & $3.5(0.87), 1.0-5.0$ & $3.4(0.72), 2.0-5.0$ \\
Total score & $13.3(3.00), 7.0-18.5$ & $13.5(3.07), 5.0-19.5$ & $13.4(3.56), 6.0-19.0$ & $13.7(3.13), 7.0-19.0$ & $13.0(2.89), 7.0-18.5$ \\
\hline
\end{tabular}

CTSR, Cognitive Therapy Scale Revised

Table 2 The criterion validity (ICC) comparing the expert rating with each CTSR-4 coder and the coder mean

\begin{tabular}{|c|c|c|c|c|c|}
\hline $\begin{array}{l}\text { CTSR-4 } \\
\text { item }\end{array}$ & $\begin{array}{l}\text { Coder A } \\
\text { ICC }(95 \% \mathrm{CI})\end{array}$ & $\begin{array}{l}\text { Coder B } \\
\text { ICC }(95 \% \mathrm{Cl})\end{array}$ & $\begin{array}{l}\text { Coder C } \\
\text { ICC }(95 \% \mathrm{CI})\end{array}$ & $\begin{array}{l}\text { Coder D } \\
\text { ICC }(95 \% \mathrm{Cl})\end{array}$ & $\begin{array}{l}\text { Coder mean } \\
\text { ICC }(95 \% \mathrm{Cl})\end{array}$ \\
\hline Structure & $.86(.77-.92)$ & $.74(.59-.85)$ & $.75(.42-.88)$ & $.71(.24-.88)$ & $.91(.82-.96)$ \\
\hline Relation & $.85(.75-.91)$ & $.71(.54-.82)$ & $.81(.69-.89)$ & $.75(.54-.87)$ & $.89(.81-.94)$ \\
\hline Concept & $.88(.80-.93)$ & $.79(.64-.88)$ & $.83(.72-.90)$ & $.82(.66-.91)$ & $.90(.83-.95)$ \\
\hline Change & $.86(.77-.92)$ & $.75(.60-.85)$ & $.80(.67-.88)$ & $.75(.53-.87)$ & $.90(.83-.94)$ \\
\hline Total score & $.93(.88-.96)$ & $.83(.72-.90)$ & $.86(.76-.92)$ & $.83(.67-.91)$ & $.96(.92-.98)$ \\
\hline
\end{tabular}

Intra-Class Correlation (ICC) was used [32, 33]. For the criterion validity of the CTSR-4, the CTSR-4 and the full CTSR were compared, and for the CTSR-4 coders' interrater agreement, the four coders' ratings were compared. A single measure analysis was conducted for the validity analysis, while both single measure and average measure analyses were conducted for the inter-rater agreement analyses. An ICC $<0.50$ was interpreted as poor, 0.500.75 as moderate, $0.75-0.90$ as good and $>0.90$ as excellent reliability [34]. According to published guidelines for calculating statistical power for inter-rater agreement, 50 observations coded by four raters should obtain a power of at least $90 \%$ to identify weak associations (ICC >0.3) between ratings [35].

\section{Results}

The CTSR-4's and the CTSR's mean values are summarized in Table 1. Overall, the CTSR-4 coders' scores were distributed evenly around the CTSR raters' mean scores with only small deviations in means and standard deviations. For most items, the CTSR-4 coders' mean scores were within 0.1 point of the expert raters' scores. The one exception was coder D's mean score on Concept which was somewhat lower than the other coders' mean scores and the expert raters' mean score.

\section{Analysis of criterion validity}

The ICC for the CTSR expert raters and each CTSR-4 coder ranged from 0.71 to 0.88 (Table 2) for the individual coders, which corresponds to moderate to good levels
Table 3 Inter-rater agreement (ICC) between the four CTSR-4 coders

\begin{tabular}{lll}
\hline CTSR-4 item & $\begin{array}{l}\text { Single measure } \\
\text { ICC }(\mathbf{9 5 \%} \mathbf{C l})\end{array}$ & $\begin{array}{l}\text { Average measure } \\
\text { ICC }(\mathbf{9 5 \%} \mathbf{C I})\end{array}$ \\
\hline Structure & $.64(.49-.76)$ & $.84(.74-.91)$ \\
Relation & $.64(.50-.76)$ & $.84(.75-.90)$ \\
Concept & $.79(.69-.87)$ & $.92(.87-.95)$ \\
Change & $.69(.56-.80)$ & $.87(.79-.92)$ \\
Total & $.76(.64-.84)$ & $.90(.84-.94)$ \\
\hline
\end{tabular}

of agreement and from 0.89 to 0.96 for the coder mean which corresponds to good to excellent agreement [34].

\section{Inter-rater agreement}

The inter-rater agreement for the four coders ranged from 0.64 (Structure and Relation) to 0.79 (Concept) in the single measure analysis, and between 0.84 (Structure and Relation) to 0.92 (Concept) in the average measure analysis (Table 3 ). This corresponds to moderate and good inter-rater reliability, respectively [34]. Thus in both analyses, Structure and Relation had the lowest interrater reliability and Conceptualization had the highest level of agreement.

\section{Discussion}

The aims of this study were to assess the criterion validity and inter-rater agreement of the CTSR-4 when evaluating short samples of CBT sessions. The validity was assessed by comparing the results from four CTSR-4 coders with 
previously expert-rated CTSR scores. The results showed ICC-values between 0.71 and 0.88 , indicating a good level of agreement $[7,11]$. While there were some minor differences between the coders, there were no systematic deviations, and the scores of the four coders were distributed evenly around the expert rater's values. The variance across items was low for all four coders, indicating that none of the specific CTSR-4 items were easier or more difficult to assess. Overall, the results showed a satisfactory criterion validity of the CTSR-4.

The inter-rater reliability results also indicated moderate to good agreement for the single measures, and good to excellent agreement for the average measures [32]. Again, these results are on par or slightly higher than those found for the CTSR in previous studies [7, 36], which is expected when collapsing an instrument into fewer items. Taken together, the results from the current analyses show that a shorter measure of competence, such as the CTSR-4, can present adequate psychometric properties when coding samples of CBT sessions. That the inter-rater reliability ICC-values were somewhat lower than the criterion validity ICC-values indicates that the CTSR-4 coders' scores were distributed both above and below the expert raters' scores so that they were actually in more agreement to the expert raters than to each other.

The CTSR- 4 was created by merging the original twelve items of the CTSR into four, generating a more global measure of CBT competence. Previous studies indicate high to very high internal consistency of the CTSR (i.e., the original study of the CTSR found alpha values of 0.92 to 0.97 [7]. In other words, there is a high probability that, for any given CBT session, items on the CTSR will receive the same score. Whether this is an effect of the instrument or the coding, or whether this is inherent in the concept of CBT competence, is unknown. The CTSR-4 investigated in this study was designed based on a theoretical understanding of CBT while recent more data-driven studies have suggested that the CTSR comprise one to three distinct factors [9, 30]. In either case, merging the CTSR items into fewer variables may be efficient when assessing general CBT competence. However, four broader items may make the CTSR-4 less sensitive to variance in $\mathrm{CBT}$ competencies. A therapist may, for example, show high competence in guided discovery, and at the same time no, or little, competence in setting up homework assignments. Such variances in CBT competencies and skills may be easier to detect with the CTSR than the CTSR-4, in which these two competencies are included within the same item. The CTSR may therefore be more useful when the goal is to map therapist competence and identify areas for further development. However, no study has yet shown that CTSR can identify such variances in CBT competence, and the results of previous studies arguably point in the direction that a competent therapist shows similar levels of competence across therapeutic domains [30,37]. Also, while most agree that some CBT components, such as setting the agenda and eliciting key cognitions, are hallmarks of quality CBT, there is very little research confirming that specific CBT components are essential for patient outcomes (however, see $[38,39]$. Recent research has also shown that sometimes skills specific to a treatment manual or model may be more important than general CBT skills for treatment outcomes $[15,40]$. Still, the CTSR, and the theoretical model of CBT competences that it relies on, remain highly important as therapist training tools, since they describe therapist competence in higher detail than the CTSR-4, and therefore more clearly present the full spectra of therapist behaviors.

A limitation of this study was the small number of coders, and the restricted number of sessions assessed. The four coders had advanced level training in CBT, and long experience in clinical work and supervising CBT therapists. It is still unclear to what degree their experiences and training may have affected their assessments, and to what degree the results can be generalized to coders with lower levels of experience and training [41]. Similarly, the fifty sessions of CBT that were assessed may have been too homogenous and not representative of CBT sessions generally. The range of the scores in both the CTSR- 4 and the CTSR items were somewhat restricted with no item receiving a score of six. To conduct rigorous psychometric testing, a larger and more varied sample of sessions may be needed. However, based on published guidelines, the study was designed to have enough power to detect low degrees of associations between variables, and all of the associations found were statistically significant. A further limitation was the informal training of the coders in using the CTSR-4. All four had experience of using the CTSR, but no formal training in using the instrument. Instead, a series of workshops were arranged, in which the coders discussed their ratings to reach consensus. Additional workshops with joint coding may have resulted in higher levels of inter-rater agreement among the coders, though this needs to be confirmed in future studies. Lastly, in this study, the association between the CTSR-4 scores and patient outcomes could not be analyzed. It is important to remember that, in the end, therapeutic competence should be decided upon the therapeutic skills and behaviors necessary to benefit patients [42].

Taken together, this study shows that a new shorter instrument, such as the CTSR-4, derived from the CTSR, can provide satisfactory criterion validity and inter-rater reliability when evaluating samples of CBT sessions. 
The correlations between the coders' and the expert raters' scores were all in the good range, indicating that the CTSR-4 can be used to efficiently rate CBT competence in a similar way as CTSR. Since the CTSR-4 comprise only four items, and can be used to analyze 15-min samples of CBT sessions, the instrument may facilitate further research of CBT competence and therapist training. Future studies need to confirm the conclusions in larger samples as well as investigate possible associations between CBT competence and patient outcomes.

\section{Acknowledgements}

Not applicable.

\section{Authors' contributions}

SA and MB identified the research question and designed the study. SA, GK, $J L$ and $M B$ analyzed the data and contributed to writing the manuscript. All authors read and approved the final manuscript.

\section{Funding}

Open access funding provided by Karolinska Institute.

\section{Availability of data and materials}

The datasets analyzed during the current study are available from the corresponding author on reasonable request.

\section{Declarations}

\section{Ethics approval and consent to participate}

All methods were performed in accordance with the Declarations of Helsinki regarding human research. All therapists and patients provided informed consent to participate in the study, and the study was approved by the Regional Ethics Committee Board in Stockholm, Sweden (No. 2018/1735-31/3).

\section{Consent for publication}

Not applicable.

\section{Competing interests}

The authors declare that they have no competing interests.

\section{Author details}

${ }^{1}$ Centre for Psychiatry Research, Department of Clinical Neuroscience, Karolinska Institutet, 17177 Stockholm, Sweden. ${ }^{2}$ Stockholm Health Care Services, Stockholm, Sweden.

Received: 28 October 2021 Accepted: 27 January 2022

Published online: 04 February 2022

\section{References}

1. Fairburn CG, Cooper Z. Therapist competence, therapy quality, and therapist training. Behav Res Ther. 2011;49(6-7):373-8. https://doi.org/10. 1016/j.brat.2011.03.005.

2. Kazantzis $\mathrm{N}$. Therapist competence in cognitive-behavioural therapies: review of the contemporary empirical evidence. Behav Chang 2003;20(1):1-12. https://doi.org/10.1375/bech.20.1.1.24845.

3. Manring J, Beitman BD, Dewan MJ. Evaluating competence in psychotherapy. Acad Psychiatry. 2003;27(3):136-44. https://doi.org/10.1176/appi. ap.27.3.136

4. Branson A, Shafran R, Myles P. Investigating the relationship between competence and patient outcome with CBT. Behav Res Ther. 2015;68:19-26.

5. Webb CA, DeRubeis RJ, Barber JP. Therapist adherence/competence and treatment outcome: a meta-analytic review. J Consult Clin Psychol. 2010;78(2):200. https://doi.org/10.1037/a0018912.
6. Young J, Beck AT. Cognitive therapy scale: rating manual. Philadelphia: Beck Institute for Cognitive Behavior Therapy; 1980.

7. Blackburn I-M, James IA, Milne DL, Baker C, Standart S, Garland A, Reichelt FK. The revised cognitive therapy scale (CTS-R): psychometric properties. Behav Cogn Psychother. 2001;29(4):431-46. https://doi.org/10.1017/ S1352465801004040.

8. Muse K, McManus F. A systematic review of methods for assessing competence in cognitive-behavioural therapy. Clin Psychol Rev. 2013:33(3):484-99.

9. Goldberg SB, Baldwin SA, Merced K, Caperton DD, Imel ZE, Atkins DC, Creed T. The structure of competence: evaluating the factor structure of the cognitive therapy rating scale. Behav Ther. 2020;51(1):113-22.

10. Trepka C, Rees A, Shapiro DA, Hardy GE, Barkham M. Therapist competence and outcome of cognitive therapy for depression. Cogn Ther Res. 2004;28(2):143-57. https://doi.org/10.1023/B:COTR.0000021536.39173.66.

11. Kazantzis N, Clayton X, Cronin TJ, Farchione D, Limburg K, Dobson KS. The Cognitive Therapy Scale and Cognitive Therapy Scale-Revised as measures of therapist competence in cognitive behavior therapy for depression: relations with short and long term outcome. Cogn Ther Res. 2018;42(4):385-97. https://doi.org/10.1007/s10608-018-9919-4.

12. Kuyken W, Tsivrikos D. Therapist competence, comorbidity and cognitivebehavioral therapy for depression. Psychother Psychosom. 2009;78(1):428. https://doi.org/10.1159/000172619.

13. Liness S, Beale S, Lea S, Byrne S, Hirsch CR, Clark DM. Multi-professional IAPT CBT training: clinical competence and patient outcomes. Behav Cogn Psychother. 2019;47(6):672-85. https://doi.org/10.1017/S1352 465819000201.

14. Weck F, Grikscheit F, Höfling V, Kordt A, Hamm AO, Gerlach AL, Alpers GW, Arolt $\mathrm{V}$, Kircher T, Pauli P. The role of treatment delivery factors in exposure-based cognitive behavioral therapy for panic disorder with agoraphobia. J Anxiety Disord. 2016;42:10-8. https://doi.org/10.1016/j. janxdis.2016.05.007

15. Bruijniks SJ, DeRubeis RJ, Lemmens LH, Peeters FP, Cuijpers P, Huibers MJ. The relation between therapy quality, therapy processes and outcomes and identifying for whom therapy quality matters in CBT and IPT for depression. Behav Res Therapy. 2021;139: 103815.

16. Liness S, Beale S, Lea S, Byrne S, Hirsch CR, Clark DM. The sustained effects of cbt training on therapist competence and patient outcomes. Cogn Ther Res. 2019;43(3):631-41. https://doi.org/10.1007/s10608-018-9987-5.

17. Kühne F, Meister R, Maaß U, Paunov T, Weck F. How Reliable are therapeutic competence ratings? Results of a systematic review and meta-analysis. Cogn Ther Res. 2020;44(2):241-57. https://doi.org/10.1007/ s10608-019-10056-5.

18. Weck F, Richtberg S, Esch S, Höfling V, Stangier U. The relationship between therapist competence and homework compliance in maintenance cognitive therapy for recurrent depression: secondary analysis of a randomized trial. Behav Ther. 2013;44(1):162-72. https://doi.org/10. 1016/j.beth.2012.09.004.

19. Impala T, Dobson KS, Kazantzis N. Does the working alliance mediate the therapist competence-outcome relationship in cognitive behavior therapy for depression? Psychother Res. 2022;32:16-28.

20. Goldberg SB, Rousmaniere T, Miller SD, Whipple J, Nielsen SL, Hoyt WT, Wampold BE. Do psychotherapists improve with time and experience? A longitudinal analysis of outcomes in a clinical setting. J Couns Psychol. 2016;63(1):1. https://doi.org/10.1037/cou0000131.

21. Moorhead S. IAPT: Improving Access to Psychiatric Training. CBT delivery by junior psychiatrists in primary care is good for the service, good for training and good for patients. Cognit Behav Therapist. 2015. https://doi. org/10.1017/S1754470X1500015X.

22. Branson A, Myles P, Mahdi M, Shafran R. The relationship between competence and patient outcome with low-intensity cognitive behavioural interventions. Behav Cogn Psychother. 2018;46(1):101-14.

23. Saxon D, Barkham M. Patterns of therapist variability: Therapist effects and the contribution of patient severity and risk. J Consult Clin Psychol. 2012;80(4):535. https://doi.org/10.1037/a0028898.

24. Swift JK, Greenberg RP. Premature discontinuation in adult psychotherapy: A meta-analysis. J Consult Clin Psychol. 2012;80(4):547. https://doi. org/10.1037/a0028226.

25. Weck F, Bohn C, Ginzburg DM, Stangier U. Assessment of adherence and competence in cognitive therapy: comparing session segments with entire sessions. Psychother Res. 2011;21(6):658-69. 
26. Roth A. A new scale for the assessment of competences in cognitive and behavioural therapy. Behav Cogn Psychother. 2016;44(5):620-4. https:// doi.org/10.1017/S1352465816000011.

27. Roth A, Pilling S. Using an evidence-based methodology to identify the competences required to deliver effective cognitive and behavioural therapy for depression and anxiety disorders. Behav Cogn Psychother. 2008;36(2):129-47. https://doi.org/10.1017/S1352465808004141.

28. Hundt NE, Mignogna J, Underhill C, Cully JA. The relationship between use of CBT skills and depression treatment outcome: a theoretical and methodological review of the literature. Behav Ther. 2013;44(1):12-26. https://doi.org/10.1016/j.beth.2012.10.001.

29. Roos J, Werbart A. Therapist and relationship factors influencing dropout from individual psychotherapy: a literature review. Psychother Res. 2013;23(4):394-418. https://doi.org/10.1080/10503307.2013.775528.

30. Beale S, Vitoratou S, Liness S. An investigation into the factor structure of the Cognitive Therapy Scale-Revised (CTS-R) in a CBT training sample. Behav Cogn Psychother. 2021;49(6):721-31.

31. Affrunti NW, Creed TA. The Factor Structure of the Cognitive Therapy Rating Scale (CTRS) in a sample of Community Mental Health Clinicians. Cogn Ther Res. 2019;43(3):642-55. https://doi.org/10.1007/ s10608-019-09998-7.

32. Koo TK, Li MY. A guideline of selecting and reporting intraclass correlation coefficients for reliability research. J Chiropr Med. 2016;15(2):155-63. https://doi.org/10.1016/j.jcm.2016.02.012.

33. Liljequist D, Elfving B, Skavberg Roaldsen K. Intraclass correlation-a discussion and demonstration of basic features. PLOS ONE. 2019;14(7): e0219854. https://doi.org/10.1371/journal.pone.0219854.

34. Portney L. Foundations of clinical research: applications to evidencebased practice. Philadelphia: FA Davis; 2020.

35. Bujang MA, Baharum N. A simplified guide to determination of sample size requirements for estimating the value of intraclass correlation coefficient: a review. Arch Orofac Sci. 2017;12(1):1-11.

36. Loades ME, Armstrong P. The challenge of training supervisors to use direct assessments of clinical competence in CBT consistently: a systematic review and exploratory training study. Cognit Behav Therapist. 2016. https://doi.org/10.1017/S1754470X15000288.

37. Vallis TM, Shaw BF, Dobson KS. The Cognitive Therapy Scale: psychometric properties. J Consult Clin Psychol. 1986;54(3):381. https://doi.org/10.1037/ 0022-006X.54.3.381.

38. Kazantzis N, Whittington C, Zelencich L, Kyrios M, Norton PJ, Hofmann SG. Quantity and quality of homework compliance: a meta-analysis of relations with outcome in cognitive behavior therapy. Behav Ther. 2016;47(5):755-72.

39. Yew RY, Dobson KS, Zyphur M, Kazantzis N. Mediators and moderators of homework-outcome relations in CBT for depression: a study of engagement, therapist skill, and client factors. Cognit Therapy Res. 2021;45:209-23.

40. Liness S, Beale S, Clark DM, Salkovskis PM, Ehlers A, Wild J. Assessing panic disorder-specific competencies: evaluation of the Cognitive Therapy Competence Scale for panic disorder. Behav Cogn Psychother. 2021;49(2):197-205.

41. Roth A, Myles-Hooton P, Branson A. Judging clinical competence using structured observation tools: a cautionary tale. Behav Cogn Psychother. 2019;47(6):736-44. https://doi.org/10.1017/S1352465819000316.

42. Shaw BF, Elkin I, Yamaguchi J, Olmsted M, Vallis TM, Dobson KS, Lowery A, Sotsky SM, Watkins JT, Imber SD. Therapist competence ratings in relation to clinical outcome in cognitive therapy of depression. J Consult Clin Psychol. 1999;67(6):837. https://doi.org/10.1037/0022-006X.67.6.837.

\section{Publisher's Note}

Springer Nature remains neutral with regard to jurisdictional claims in published maps and institutional affiliations.

Ready to submit your research? Choose BMC and benefit from:

- fast, convenient online submission

- thorough peer review by experienced researchers in your field

- rapid publication on acceptance

- support for research data, including large and complex data types

- gold Open Access which fosters wider collaboration and increased citations

- maximum visibility for your research: over 100M website views per year

At BMC, research is always in progress.

Learn more biomedcentral.com/submissions 